\title{
Polymerization of Tetraethoxysilane by Using Remote Argon/dinitrogen oxide Microwave Plasma
}

\author{
Tae Il Chun ${ }^{\dagger}$ and Volker Rossbach ${ }^{1}$ \\ Dong-eui University, Department of Clothing \& Textiles, Pusan 614-714, Korea \\ ${ }^{1}$ Dresden University of Technology, Institute of Macromolecule Chemistry and Textile Chemistry, D 01062 Dresden, Germany
}

(Received: April 9, 2009/Revised: May 22, 2009/Accepted: June 5, 2009)

\begin{abstract}
Polymerization of tetraethoxysilane on a glass substrate was investigated by remote microwave plasma using argon with portions of nitrous oxide as carrier gas. Transparent layer like a thickness of $0.5 \mu \mathrm{m}-3 \mu \mathrm{m}$ were obtained, differing in chemical composition, depending on plasma power and treatment time as well as on ageing time. In general the milder the treatment and the shorter the ageing was, the higher was the content of organic structural elements in the layer. We have identified that the chemical structure of our samples composed of mainly $\mathrm{Si-O}$ and $\mathrm{Si}^{-} \mathrm{C}^{-}$groups containing aliphatics, carbonyl groups. These results were obtained by X-ray photon spectroscopy, Fourier transformed infrared spectroscopy, and scanning electron microscope combined with Energy dispersive X-ray spectroscopy.

Keywords: remote micro wave plasma, plasma polymerization and deposition, plasma enhanced chemical vapour deposition, tetraethoxysilane, scanning electron microscope, energy dispersive X-ray spectroscopy, X-ray photon spectroscopy, fourier transformed infrared spectroscopy
\end{abstract}

\section{Introduction}

In recent years, plasma polymerization and deposition of organosilicone compounds has been carried out in order to prepare thin oxide films with good dielectric properties and high thermal stability. Most of works have been focused on applications as insulated films for microelectronic devices. Polymerization and deposition of the organosilicone monomers, hexamethyldisiloxane (HMDSO) or tetramethylsilane(TMS) by using glow discharge, radio frequency(RF), and microwave (MW) direct plasma system were fully described in the literature ${ }^{1-8)}$. Plasma enhanced chemical vapour deposition(PECVD) of silicone dioxide $\left(\mathrm{SiO}_{2}\right)$ thin film has been investigated by using $\mathrm{RF}(13.56 \mathrm{MHz})$ plasma operating at a relatively low plasma power"). The effect of plasma treatment was generally discussed in the term of plasma variables such as the nature of the gas used, the pressure of in the discharge, the power of the plasma, the reactor geometry, and the frequency used for excitation. Comparing to direct plasma system, detail studies have not been reported to date by using the remote MW plasma, which was known as a developed system adequate for plasma deposition.

The modern MW plasma based surface processing have been continuously increasing because of the process uniformity, reliably controlled and highly effective sources of various ions and radicals ${ }^{10-12)}$. The slot antenna MW plasma source is beginning to be used for remote plasma deposition on polycarbonate substrate with the monomer HMDSO by argon and oxygen gases ${ }^{13,14)}$. In our previous paper ${ }^{15}$, the influence of remote plasma activated $\mathrm{Ar} /$ dinitrogen oxide $\left(\mathrm{N}_{2} \mathrm{O}\right)$ gas mixture on Polyethylenetetrafluoroethylene had been examined. In this paper, we have focused the experiment on the polymerization and deposition of tetraethoxysilane (TEOS) by using remote $\mathrm{Ar} / \mathrm{N}_{2} \mathrm{O}$ microwave

${ }^{\dagger}$ Corresponding author. Tel.: +82-51-890-1600; Fax.: +82-51-890-1579; e-mail: tichun@deu.ac.kr 
plasma on the glass substrate. Results on the base of experimental studies are given for the following points; 1 . The effect of MW power on the deposition rate of TEOS using $\operatorname{argon} / \mathrm{N}_{2} \mathrm{O}$ gas mixtures, 2. The deposited layer was determined by SEM equipped with EDXS, and 3. The chemical composition of the bulk and the surface of deposited layer by Fourier transformed infrared spectroscopy(FT-IR-ATR), and X-ray photon spectroscopy.

\section{Experimental}

\subsection{Materials and Analytical methods}

General slide glasses for light microscopic view (thickness $1.11 \times 103 \mu \mathrm{m}$ ) were used as a substrate. All samples were cleaned by ethyl acetate, acetone and methyl alcohol before use. The organosilicone compound used in this study was TEOS(Tetraethoxysilane, Acros Organics, $\mathrm{C}_{8} \mathrm{H}_{2} \mathrm{O}_{4} \mathrm{Si}$, molecular mass $208.33 \mathrm{~g} /$ mole, MP $\left.37^{\circ} \mathrm{C}, \mathrm{d} 0.9350 \mathrm{~g} / \mathrm{mL}, \mathrm{nd}^{20} 1.3825\right)$. A Nicolet 5PC FT-IR spectrophotometer equipped with $\mathrm{Xe} / \mathrm{Se}$ detector has been used for FT-IR spectroscopy. Infrared spectra were recorded at the resolution of $4 \mathrm{~cm}^{-1}$ by coding 256 interferograms. XPS measurement were performed in an $\mathrm{X}^{-}$ Probe TM spectrometer(model 206, SSI, Mountain View, California, USA) as described previously ${ }^{15}$. For SEM investigations in combination with EDX measurements, the Philips XL 30 type spectrometer was used. UV-Visible spectrophotometer was used for transmittance of glass samples.

\subsection{Remote MW plasma processing}

Plasma polymerization and deposition on the glass with TEOS was carried out by means of a remote MW plasma system. The dense Argon $/ \mathrm{N}_{2} \mathrm{O}$ gas plasma was formed using a MW source of the SLAN I type based on the slot antenna principle (JE PLASMA CONSUL, GmbH, Germany, 2KW, 2.46GHz). Typical experimental conditions are as follows: in the evacuated steel reactor $(0.02 \mathrm{mbar})$ various gas flow of $\mathrm{Ar}[0.3$ up to $1.0 \mathrm{slm}$ (standard liter per minute)] and
$\mathrm{N}_{2} \mathrm{O}$ gas (corresponding to a portion of $8.75 \mathrm{vol}$ $\%$ in the mixture) were introduced to the top inside in a quartz cylinder up to reactor pressures of between 0.2 and 1.0mbar. The $\mathrm{Ar} / \mathrm{N}_{2} \mathrm{O}$ gas plasma was ignited by various electrical generator powers $(200 \mathrm{~W} \sim 1,400 \mathrm{~W})$. The TEOS monomer stored in a thermostatic reservoir at $35^{\circ} \mathrm{C}$ was transferred into the reactor by a gas ring system outside of the $\mathrm{Ar} / \mathrm{N}_{2} \mathrm{O}$ gas plasma by a constant argon carrier gas flow $(0.05 \mathrm{slm})$. The glass substrates for comparably experiments were positioned downstream on the plasma excitation zone and monomer input system. The deposition temperature was maintained between $26^{\circ} \mathrm{C}$ and $33^{\circ} \mathrm{C}$ without substrate heating and the deposition time was varied between $15 \mathrm{~min}$ and $60 \mathrm{~min}$.

\section{Results and Discussion}

\subsection{Deposition rate}

Calculation of the deposition rate was based on the change in weight per unit area and minute $\left(\mathrm{mg} / \mathrm{cm}^{2} \cdot \mathrm{min}\right)$ regarding to the weight difference on the glass substrate with defined area. The layer thickness varied with between 0.1 and $3 \mu \mathrm{m}$ and depends on the deposition parameters, especially on the plasma power. With increasing plasma power the formation rate also increase (Fig. 1).

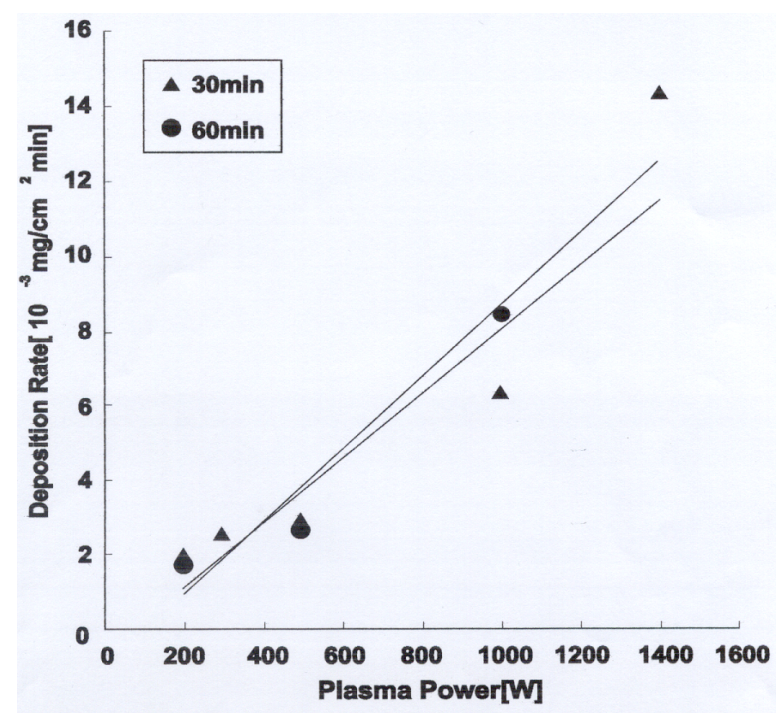

Fig. 1. The relationship between the deposition rate of TEOS and plasma power. 
Table 1. FT-IR Band Assignment

\begin{tabular}{ll}
\hline Band $\left(\mathrm{cm}^{-1}\right)$ & Assignment \\
\hline $3400-3200(m)$ (bonded), and 950-830 $(m)$ & $\mathrm{Si}-\mathrm{OH}, \mathrm{H}_{2} \mathrm{O}$ \\
$32000-3600$ & $\mathrm{OH}$ stretch, bonded \\
2964 & $\mathrm{C}-\mathrm{H}$ stretch, asym. $\left(\mathrm{CH}_{3}\right)$ \\
2906 & $\mathrm{Si}-\mathrm{O}-\mathrm{C}_{2} \mathrm{H}_{5}, \mathrm{C}_{2} \mathrm{H}_{5}-\mathrm{OH}, \mathrm{C}_{2} \mathrm{H}_{5}-\mathrm{O}-$ \\
2900 & $\mathrm{O}-\mathrm{CH}_{2}$ \\
1718,1749 & $\mathrm{C}=\mathrm{O}$ stretching mode, hydrogen bonded carbonyl \\
1450 & $\mathrm{CH}_{2}$ deformation \\
1421,1402 & $\mathrm{Si}-\mathrm{O}-\mathrm{CH}_{3}$ deformation, asym. \\
1370 & $\mathrm{Si}-\mathrm{CH} \mathrm{H}_{3}$ deformation \\
$1130-900$ & $\mathrm{Si}-\mathrm{O}-\mathrm{Si}, \mathrm{Si}-\mathrm{O}-\mathrm{R}$ \\
\hline
\end{tabular}

\subsection{FT-IR-ATR and UV-Visible spectra}

Fig. 2 showed ATR spectra of the plasma/ TEOS treated and untreated glass for comparison. By band assignment several functional groups (among them also organosilicone structures) could be identified on the basis of the references as shown in Table 1.

The major broad peak in untreated glass at around $1000-900 \mathrm{~cm}^{-1}$ have been assigned to $\mathrm{Si}-\mathrm{O}$ -Si stretching bands. On the other hand, there are several other bands of plasma/TEOS deposited sample, $\mathrm{Si}-\mathrm{O}-\mathrm{R}$ at $1130-1000(s) \mathrm{cm}^{-1}$ and $\mathrm{Si}^{-\mathrm{O}}$ $\mathrm{CH}_{2^{-}}$at $1175^{-1160}(\mathrm{~m}) \mathrm{cm}^{-1}$ which also originate from TEOS groups. The two bands in the range $1750-1640 \mathrm{~cm}^{-1}$ in the spectra of treated samples corresponding to the stretching vibration of the $\mathrm{C}=\mathrm{O}$ group. FT-IR spectra showed bands for $\mathrm{Si}^{-}$ $\mathrm{C}$ at $855-780 \mathrm{~cm}^{-1}, \mathrm{Si}-\mathrm{O}-\mathrm{R}$ at $950 \mathrm{~cm}^{-1}, \mathrm{Si}-\mathrm{O}-\mathrm{Si}$ and $\mathrm{Si}-\mathrm{O}-\mathrm{C}$ at around $1100-1030 \mathrm{~cm}^{-1}$. Intensity of the carbonyl bands in the range $1820-1620 \mathrm{~cm}^{-1}$, two peaks of $-\mathrm{C}-\mathrm{H}$ stretching in the range 2800$3000 \mathrm{~cm}^{-1}$, and $-\mathrm{CH}_{2}$ bending at $1450 \mathrm{~cm}^{-1}$ indicated that some polymeric structure were deposited on the glass surface. In the spectrum of untreated glass there is no distinguishing feature can be seen between $3800-2600 \mathrm{~cm}^{-1}$ and $1800-1300 \mathrm{~cm}^{-1}$. However, the deposited surface with TEOS by remote microwave plasma the distinct $-\mathrm{C}-\mathrm{H}$ and $-\mathrm{C}=\mathrm{O}$ stretching frequency can be observed.

We have identified that the chemical structure of our samples composed of mainly $\mathrm{Si}^{-} \mathrm{O}^{-}$and $\mathrm{Si}-\mathrm{C}-$ groups containing aliphatics and carbonyl groups.

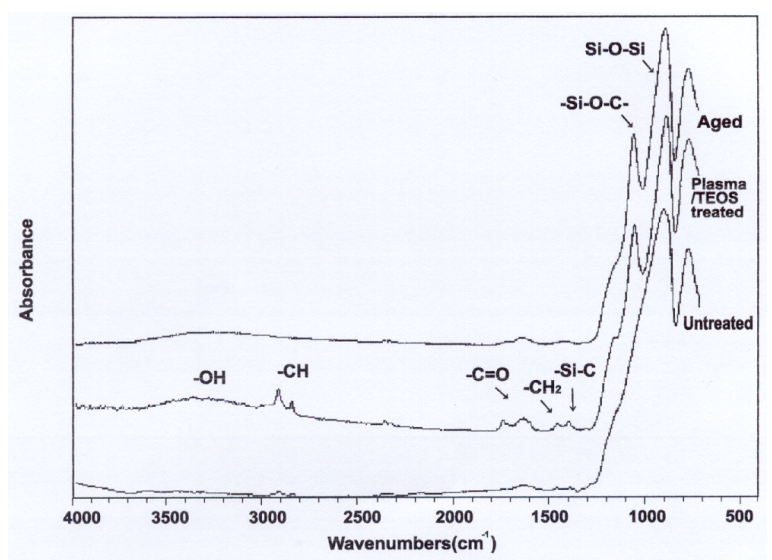

Fig. 2. FT-IR-ATR spectra of untreated plasma/TEOS deposited glass.

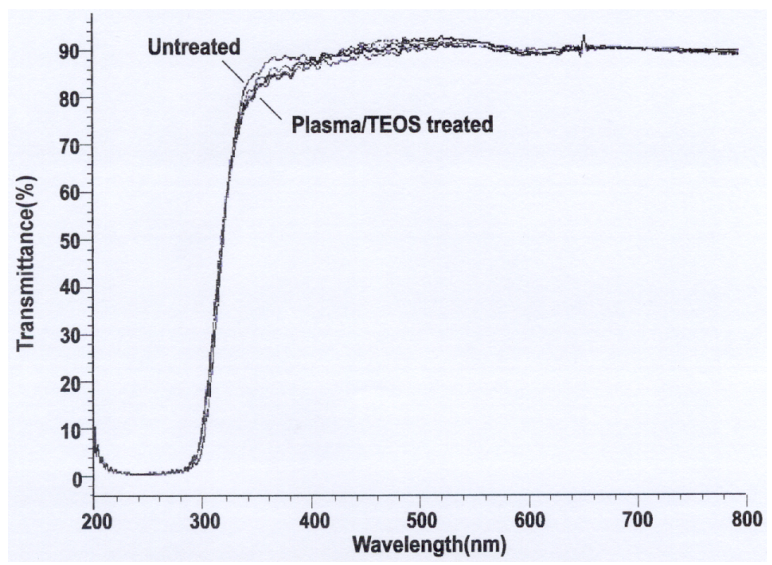

Fig. 3. UV-Visible spectra of untreated and plasma/ TEOS treated glasses.

After one month aging at room temperature, these peaks diminished. This result indicated that the ethoxy groups of some oligomers deposited on the surface reacted with moisture. It is well known that the ethoxy group can react with water, alcohols and silanol even in the presence 
Table 2. Elemental composition in atomic $\%$ of plasma/TEOS treated samples

\begin{tabular}{lccccc}
\hline & Atomic species $\%$ & $\mathrm{C}$ & $\mathrm{O}$ & $\mathrm{N}$ & $\mathrm{Si}$ \\
Plasma Power & & $1 \mathrm{~s}$ & $1 \mathrm{~s}$ & $1 \mathrm{~s}$ & $2 \mathrm{p}$ \\
\hline $500 \mathrm{~W}^{a}$ & & 68.31 & 20.93 & 0.62 & 8.56 \\
$1,000 \mathrm{~W}^{b}$ & & 22.78 & 47.96 & 1.19 & 23.83 \\
\hline
\end{tabular}

Treatment conditions of ${ }^{a}$ and ${ }^{b}$ : the reaction time was $60 \mathrm{~min}$, the vacuum pressure 0.5 mbar, TEOS flow rate $0.05 \mathrm{slm}$.

${ }^{a}$ : $0.3 \mathrm{slm} \mathrm{Ar} / 8.75$ vol \% $\mathrm{N}_{2} \mathrm{O},{ }^{b}: 1.0 \mathrm{slm} / 8.75$ vol $\% \mathrm{~N}_{2} \mathrm{O}$.

Table 3. Carbon species in atomic $\%$ of plasma/TEOS treated samples

\begin{tabular}{lccc}
\hline \multirow{2}{*}{ Binding Energies } & \multicolumn{3}{c}{$\mathrm{C}-\mathrm{species}$} \\
\cline { 2 - 4 } Plasma Power & $\mathrm{C}-\mathrm{C}, \mathrm{C}-\mathrm{H}$ & $\mathrm{C}-\mathrm{O}$ & $\mathrm{NH}-\mathrm{C}=\mathrm{O},-\mathrm{O}-\mathrm{C}=\mathrm{O}$ \\
& $285.0 \mathrm{eV}$ & $286.5 \mathrm{eV}$ & $288 \mathrm{eV}$ \\
\hline $500 \mathrm{~W}^{a}$ & 60.87 & 4.19 & 3.64 \\
$1,000 \mathrm{~W}^{b}$ & 17.79 & 1.78 & 3.21 \\
\hline
\end{tabular}

Treatment conditions of ${ }^{a}$ and ${ }^{b}$ see Table 2 .

of small amounts of moisture or bases. When the organic residue bearing the carbofunctional group is attached to the silicone via a heteroatom such as $\mathrm{O}, \mathrm{S}$, or $\mathrm{N}$, this bond is too sensitive to hydrolysis ${ }^{16}$.

The ethoxy groups in TEOS, $\mathrm{Si}-\left(\mathrm{O}^{-} \mathrm{C}_{2} \mathrm{H}_{5}\right)_{4}$, are reactive enough under mild condition to form $\mathrm{Si}$ $-\mathrm{O}-\mathrm{Si}$ with $-\mathrm{OH}$ or $\mathrm{Si}-\mathrm{O}-$ groups. Thus it can be taken for sure that the oligomers react also during the plasma treatment by condensation(c.f. $\mathrm{Si}-\mathrm{O}-\mathrm{Si}$ ), and oxidation(c.f. $\mathrm{C}=\mathrm{O}$ ) and more complex reactions(c.f. Si-C). Moreover a functional group in position renders the $\mathrm{Si}-\mathrm{C}$ bond more sensitive to hydrolysis. In this point of view, it is reasonable to think that the oligomers in the samples proceed further reaction.

Fig. 3 showed that there was not a significant difference in UV-visible region. It showed that a transparent film was deposited on glass substrate. Plasma/TEOS deposited glasses have slightly low transmittance in visible regions depending on the deposited thickness.

\subsection{XPS}

XPS results for the plasma/TEOS deposited surface and reference have been shown in Table 3 . Due to the treatment of Plasma/TEOS, aliphatic carbon like C-C, C-H $(285 \mathrm{eV})$, and $\mathrm{C}-\mathrm{O}$ bonded carbon $(286.5 \mathrm{eV})$ can be detected.
The concentration of $\mathrm{O}$ atom increased and a small mount of $\mathrm{N}$ atom peak at $401 \mathrm{eV}$ was considered as arising from the nitrogen atom $\left(\mathrm{N}_{1 \mathrm{~s}}\right)$ during the $\mathrm{Ar} / \mathrm{N}_{2} \mathrm{O}$ plasma treatment. The plasma /TEOS treated surfaces showed even a far more pronounced changed atomic composition.

With increasing plasma power, the aliphatic carbons decreased, $\mathrm{O}$ and $\mathrm{Si}$ increased.

In addition to quantitative change, some new structures can be detected, as ester carbon $\mathrm{O}^{-}$ $\mathrm{C}=\mathrm{O}(288 \mathrm{eV}), \mathrm{Si}(104 \mathrm{eV})$ and $\mathrm{O}(532 \mathrm{eV})$.

The $\mathrm{O}_{1 \mathrm{~s}}$ spectrum contains contributions from silicone group as well as carbonyl and carboxyl groups combined with aliphatic carbons.

As shown in Table 2, 3 and Fig. 3, comparing sample a to sample b, the aliphatic carbon species of sample a, which was produced at a relatively low plasma power $500 \mathrm{~W}$, were detected about three times as much as those of sample b. On the other hand, $\mathrm{Si}$ atomic content of sample a was reduced from $23.83 \%$ to $8.56 \%$. The correlation is observed between the atomic concentration of $\mathrm{Si}$ and that of $\mathrm{C}_{1 \mathrm{~s}}$ and $\mathrm{O}_{1 \mathrm{~s}}$. The contents of atomic \% depend on the plasma treatment condition. XPS analysis showed that increasing plasma power and $\mathrm{Ar} / \mathrm{N}_{2} \mathrm{O}$ gas flow rate, $\mathrm{Si}$ atomic concentration increased and aliphatic carbons decreased. The representative XPS spectra showed in Fig. 4. C-C, C-H at $285 \mathrm{eV}$ 

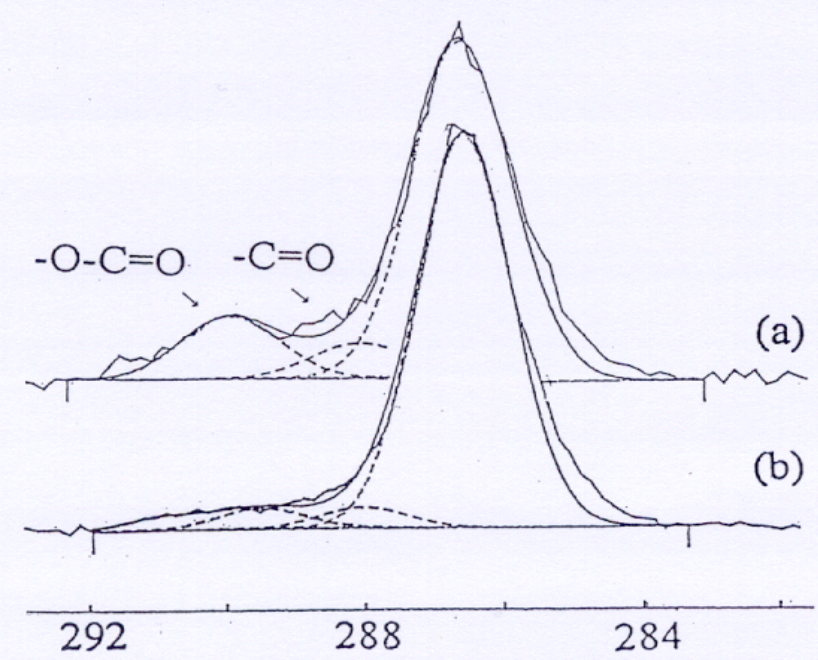

\section{4}

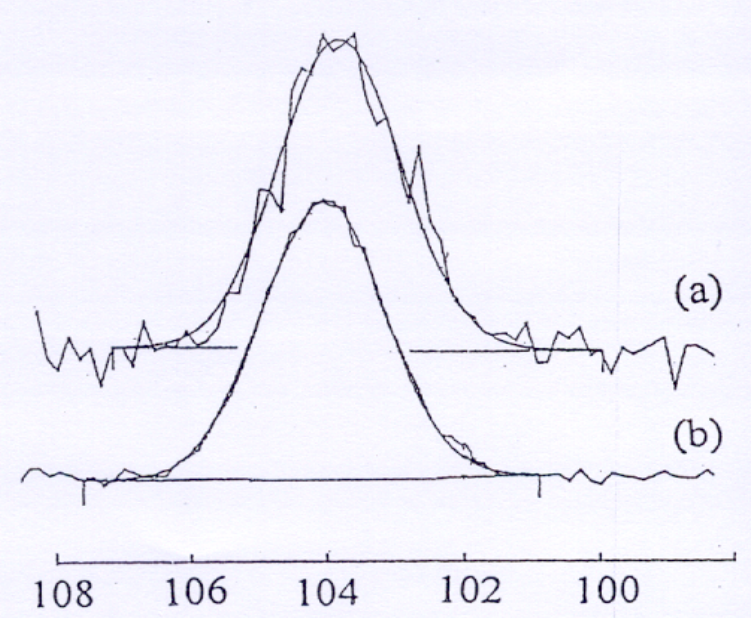

Fig. 4. XPS spectra of untreated and plasma/TEOS treated glasses.(Treatment conditions see Table 2).

was strongly increased due to alipathic carbon. The $-\mathrm{C}=\mathrm{O}$ peak at $286.5 \mathrm{eV}$ and $\mathrm{NH}-\mathrm{C}=\mathrm{O}$, $-\mathrm{O}-$ $\mathrm{C}=\mathrm{O}$ at around $288 \mathrm{eV}$ were detected. The single $\mathrm{Si}$ peak at $104 \mathrm{eV}$ in sample $\mathrm{b}$ represented $\mathrm{Si}^{-}$ $\mathrm{O}_{\mathrm{x}}{ }^{14)}$ was detected. Elementary analysis of the deposited layers which produced at a low plasma power(200W-300W) showed C(25.15-24.80 wt\%), $\mathrm{H}(5.11-5.01 \mathrm{wt} \%)$, and small amount of $\mathrm{N}\left(0.78^{-}\right.$ $0.80 \mathrm{wt} \%)$. This result also indicated that $\mathrm{C}$ atoms presented a far high content at a relatively low plasma power. The existence of carbon based organic structure containing silicone oxide was suggested a results of the above investigating data.

\subsection{SEM with EDXS}

SEM of selected samples treated under different plasma conditions are shown in Fig. 5.

The thickness of the deposited layer was varied between $0.5-3.0 \mu \mathrm{m}$ depending on plasma variables mainly plasma power and reaction time.

The deposited layer has without pinholes, a good adhesion and no curling effect which was shown in our previous report ${ }^{15)}$. It is considered that inorganic glass solid has a good affinity to the newly formed layer, which has almost same chemical structure as the glass substrate, and the firmly adhered layer reduced internal stress.

Fig. 5 showed the well-formed layers, which were produced to the monomer flow direction at
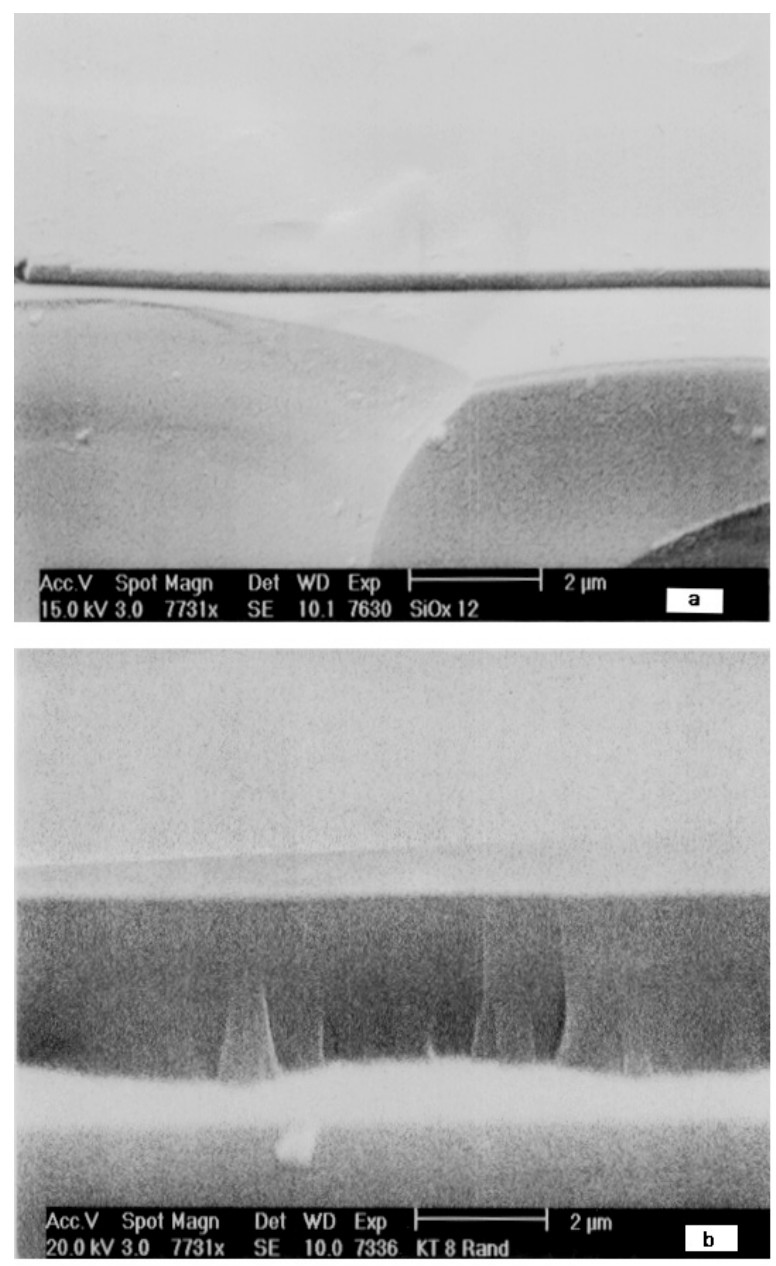

Fig. 5. SEM of the Plasma/TEOS treated layers on the glass substrate.(Treatment conditions of sample a and $\mathrm{b}$ : The reaction time $30 \mathrm{~min}$, and TEOS flow rate $0.05 \mathrm{~s} / \mathrm{m}$. For sample a, $0.2 \mathrm{mb}, 300 \mathrm{~W}, 0.3 \mathrm{slm} \mathrm{Ar} / 8.75$ vol \% $\mathrm{N}_{2} \mathrm{O}$, and for sample b, 0.5mb, 200W, $1.0 \mathrm{slm}$ $\mathrm{Ar} / 8.75$ vol \% $\mathrm{N}_{2} \mathrm{O}$ ). 

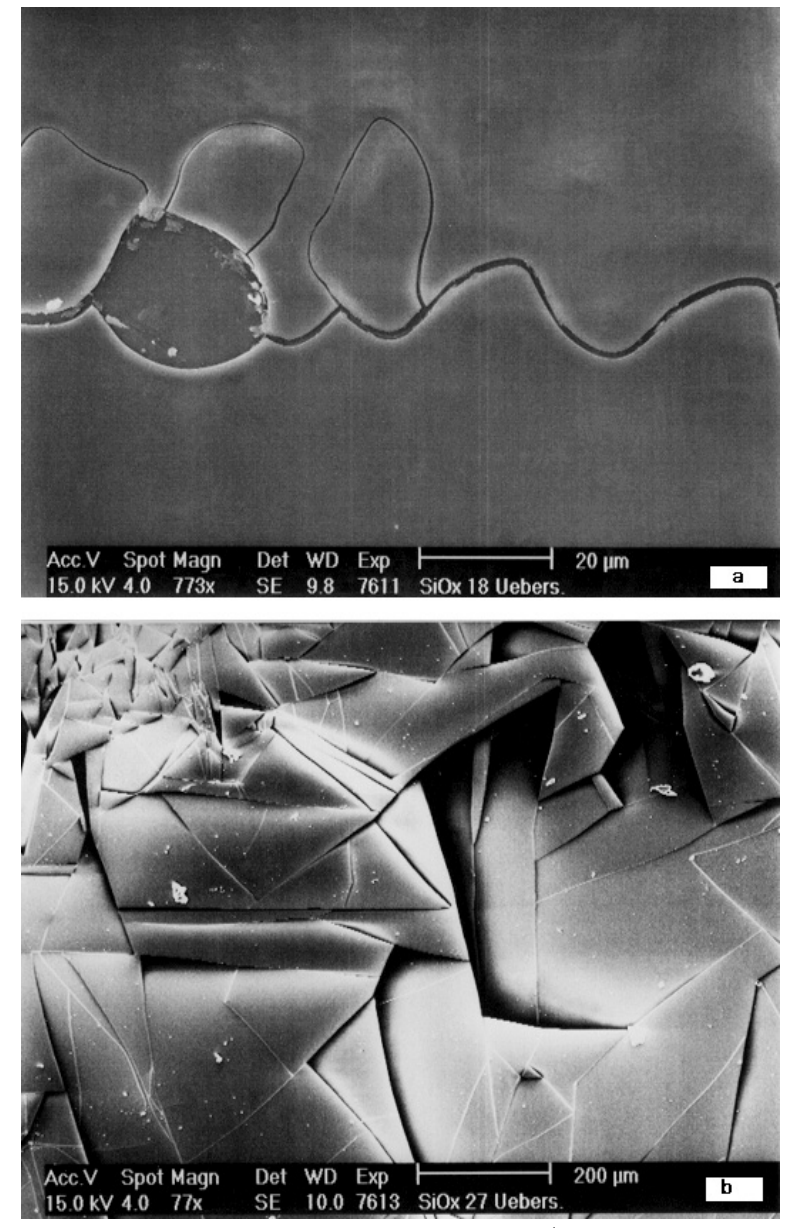

Fig. 6. SEM of the surface of Plasma/TEOS deposited layer.(Treatment conditions of sample $\mathrm{a}$ and $\mathrm{b}$ : the reaction time was $60 \mathrm{~min}$, TEOS flow rate $0.05 \mathrm{~s} / \mathrm{m}$; a, $1 \mathrm{mb}, 200 \mathrm{~W}, 0.3 \mathrm{slm} \mathrm{Ar} / 8.75 \mathrm{vol} \% \mathrm{~N}_{2} \mathrm{O}$, and b, 0.5mb, $500 \mathrm{~W}, 0.6 \mathrm{slm} \mathrm{Ar} / 8.75 \mathrm{vol} \% \mathrm{~N}_{2} \mathrm{O}$ ). a relatively low plasma power (200W, 300W). By aging, the soft layer produced at a relatively low plasma power and $\mathrm{Ar} / \mathrm{N}_{2} \mathrm{O}$ gas flow cracked slowly through internal reaction induced stress from surface to the bottom(Fig. 6-a).

But increasing plasma power and the plasma gas flow, we got the hard surface and it was cracked like a thin glass(Fig. 6-b).

The EDXS spectra in Fig. 7 showed the chemical composition of the layer. Three peaks typical for $\mathrm{C}, \mathrm{O}$, and $\mathrm{Si}$ appeared for the plasma /TEOS treated surface although differing in strength. This spectrum indicated that the deposit layer was predominantly composed of $\mathrm{Si}$ and $\mathrm{O}$, but there were also a trace of $\mathrm{C}$ elements even though produced at a high plasma power 1,000W. This is a good accordance with XPS and FT-IRATR spectra.

\section{Conclusion}

With $\mathrm{Ar} / \mathrm{N}_{2} \mathrm{O}$ carrier gas and appropriate remote $\mathrm{M} / \mathrm{W}$ plasma conditions thin and transparent film layers were obtained with tetraethoxysilane.

The polymeric layer was deposited due to a high content of aliphatic organic structural elements. By increasing the power and treatment time, hard and brittle layers were obtained which contented a higher concentration of silicone.

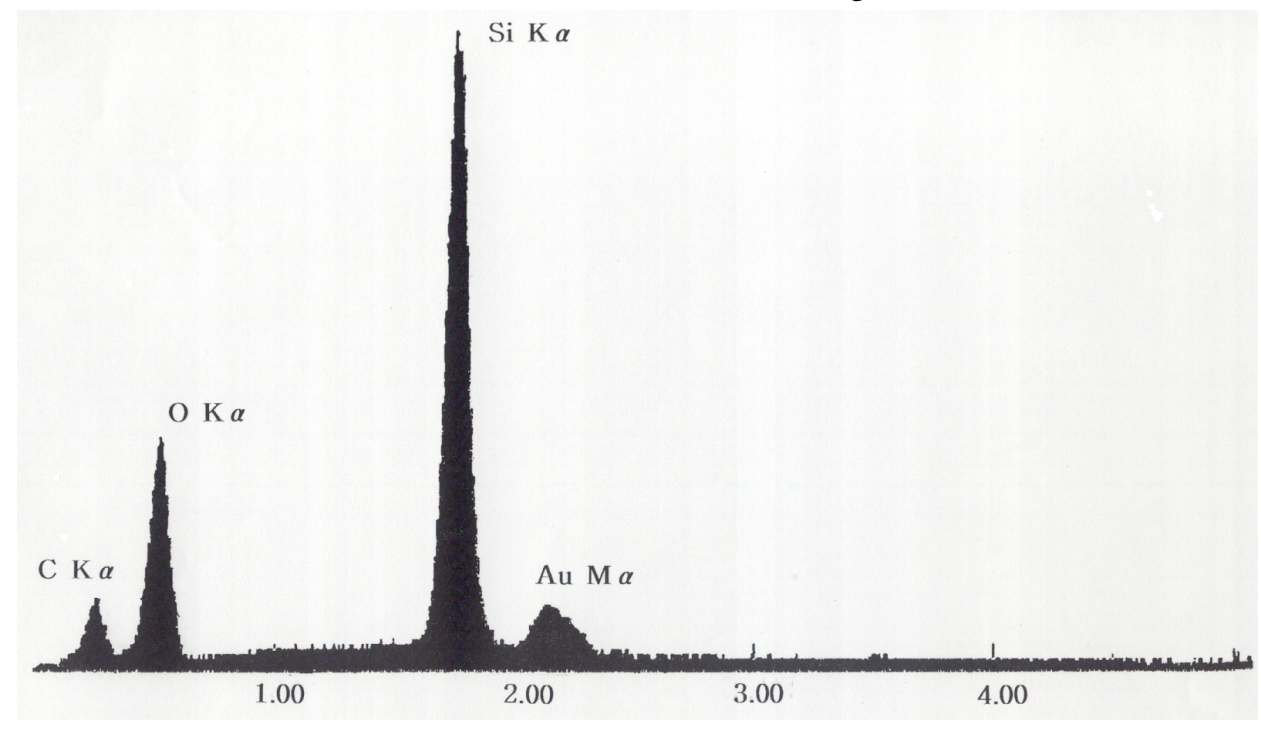

Fig. 7. Energy dispersive $X$-ray spectra of the plasma/TEOS treated layer.(Treatment conditions: $0.5 \mathrm{mb}, 1,000 \mathrm{~W}, 1.0 \mathrm{slm} \mathrm{Ar} / 8.75$ vol $\% \mathrm{~N}_{2} \mathrm{O}$, TEOS flow rate $0.05 \mathrm{slm}$, and the reaction time $60 \mathrm{~min})$. 
We have identified that the chemical structure of samples composed of mainly $\mathrm{Si}^{-} \mathrm{O}^{-}$and $\mathrm{Si}^{-} \mathrm{C}^{-}$ groups containing aliphatics, carbonyl groups and also small amount of nitrogen.

The existence of carbon based organic structure containing silicone oxide was suggested a results of the above investigating data.

\section{Acknowledgements}

This work was supported by Dong-Eui University Grant(2006AA219).

\section{References}

1. Y. Segui and Buiai, Gas Discharge in Hexamethyldisiloxane, J. Appl. Polym. Sci., 20, 1611(1976).

2. A. M. Wróbel, M. Kryszewski and M. Gazicki, Structure of Glow Discharge Polysilazane Thin Films, Polymer, 17, 678(1976).

3. A. M. Wróbel, M. R. Wertheimer, J. Dib, and H. P. Schreiber, Polymerization of Organosilicones in Microwave Discharges, J. Macromol. Sci. Chem., A14(3), 321(1980).

4. Ichiro Tajima and Minoru Yamamoto, Spectroscopic Study on Chemical Structure of PlasmaPolymerized Hexamethyldisiloxane, J. Polym. Sci., Polym. Chem. Ed., 23, 615(1985).

5. I. H. Coopes and H. J. Griesser, The Structure of Organosilicon Plasma-Polymerized Coatings of Metal Substrates, J. Appl. Polym. Sci., 37, 3413(1989).

6. F. Kokaki, T. Kubota, M. Ichiyo, and K. Wakai, Plasma Diagnostics and Structure of Plasma Polymers of Tetramethylsilane, J. Appl. Polym. Sci., Appl. Polym. Symp., 42, 197(1988).

7. Shide Cai, Jianglin Fang, and Xuehai Yu, Plasma Polymerization of Organosiloxanes, J. Appl. Polym. Sci., 44, 135(1992).
8. Güneri Akovali, Zakir M. O. Rzaev and D G. Mamedov, Plasma Surface Modification of Polyethylene with Organosilicon and Organotin Monomers, Eur. Polym. J., 32(3), 375(1996).

9. Shashank C. Deshmukh and Eray S. Aydil, Investigation of Low Temperature $\mathrm{SiO}_{2}$ Plasma Enhanced Chemical Vapor Deposition, $J$. Vac. Sci. Technol., B14(2), 738(1996).

10. Harold F. Winters, et al., Coatings and Surface Modification Using Low Pressure Non-Equilibrium Plasmas, Material Science and Engineering, 70, 53(1985).

11. G. Beamson, W. J. Brennan, D. K. Clark, and J. Howard, Modification of Surfaces and Surface Layers by Non Equilibrium Processes, Physica Scripta., T23, 249(1988).

12. V. Dušek, and J. Musil, Microwave Plasmas in Surface Treatment Technologies, Czech. J. Phys., 40, 1185(1990).

13. D. Korzec, K. Traub, F. Werner, and J. Engemann, Remote deposition of scratch resistant films by use of slot Antenna microwave plasma sources, Thin Solid Films, 143, 281(1996).

14. Yasumi Yamada, Shigeru Tasaka, and Norihiro Inagaki, Effect of Remote Oxygen-Plasma for $\mathrm{SiO}_{\mathrm{x}}$ Film Preparation, Kobunshi Ronbunshu, 53(1), 33(1996).

15. Tae Il Chun, Suk Chul Choi, Christine Täschner, Albrecht Leonhardt, Robert Kaufmann, Carsten Rehwinkel, Volker Rossbach, Surface Modification of Polytetrafluoroethylene with Tetraethoxysilane by Using Remote Argon/ Dinitrogen Oxide Microwave plasma, J. Appl. Poly. Sci., 76, 1207(2000).

16. Hans R. Kricheldorf, "Silicon in Polymer Synthesis", Springer-Velag, Berlin, Chapter 7, p.408, 1996. 